\title{
Initiation of antidepressant therapy: do patients follow the GP's prescription?
}

\author{
Erica CG van Geffen, Helga Gardarsdottir, Rolf van Hulten, Liset van Dijk, \\ Antoine CG Egberts and Eibert R Heerdink
}

\begin{abstract}
Background

The question whether patients actually start drug taking after having received a first antidepressant prescription is often overlooked.
\end{abstract}

Aim

To determine the incidence of patients who do not fill or fill only a single antidepressant prescription at the pharmacy, and to identify associated patient characteristics.

Design of study

Retrospective study linking a general practice to a pharmacy dispensing database.

Setting

General practice in the Netherlands.

\section{Method}

Study population: patients who received a first-time antidepressant prescription from a GP. Three patient groups were identified: patients who did not fill the prescription (non-fillers); patients who filled only a single prescription (single Rx-fillers); and patients who filled at least two consecutive prescriptions. Non-fillers and single $\mathrm{Rx}$-fillers were combined into a group of decliners.

\section{Results}

Of all 965 patients, 41 (4.2\%) did not fill the prescription, and $229(23.7 \%)$ filled only a single prescription. Patients who consulted their GP for a non-specific indication, rather than for depression, anxiety, panic, or obsessive-compulsive disorder, were almost three times more likely (odds ratio $[\mathrm{OR}]=2.7$, $95 \%$ confidence interval $[\mathrm{Cl}]=1.8$ to 3.9 ) to decline treatment. Further, the risk of declining was almost fivefold higher $(\mathrm{OR}=4.8,95 \% \mathrm{Cl}=2.1$ to 11.3$)$ in nonWestern immigrants, and almost twofold higher $(\mathrm{OR}=1.8,95 \% \mathrm{Cl}=1.2$ to 2.8$)$ in patients $>60$ years of age.

\section{Conclusion}

Over one in four patients who receive a first-time antidepressant prescription decline treatment; they either do not initiate drug taking or do not persist with antidepressant use for longer than 2 weeks.

\section{Keywords}

antidepressants; anxiety; depression; patient nonadherence; treatment refusal.

\section{INTRODUCTION}

Initiation of drug taking is a complicated process, as it involves patients and physicians making consecutive decisions. When faced with a health concern, the patient needs to recognise it as a problem and to decide whether to consult a physician. Thereupon, the physician must be able to recognise and diagnose the patient's health problem and may propose treatment, including drug treatment. If the physician-patient encounter results in a prescription for drug treatment, the patient subsequently has to decide whether to present the prescription at the pharmacy for dispensing. Having filled the prescription, the patient has to initiate treatment by taking the first tablet. And finally, the patient has to decide to persist in drug taking. Although this factual sequence of actions leads to a simple dichotomous decision to initiate or not to initiate drug treatment, it in fact involves a complex cognitive process taking many considerations into account. The decision to initiate drug taking is influenced by the way in which patients evaluate their personal need for medication relative to their concerns about potential negative effects of taking it., ${ }^{1,2}$ Patients evaluate whether the physician's advice to start drug

ECG van Geffen, PhD, PharmD; H Gardarsdottir, PharmD, PhD student; $R$ van Hulten, PhD, PharmD; ER Heerdink, PhD, associate professor, Division of Pharmacoepidemiology and Pharmacotherapy, Utrecht Institute for Pharmaceutical Sciences, Faculty of Science, Utrecht University, the Netherlands. L van Dijk, PhD, Netherlands Institute for Health Services Research (NIVEL), Utrecht, the Netherlands. ACG Egberts, PhD, PharmD, professor of clinical pharmacy, Division of Pharmacoepidemiology and Pharmacotherapy, Utrecht Institute for Pharmaceutical Sciences, Faculty of Science, Utrecht University, and Department of Clinical Pharmacy, University Medical Centre, Utrecht, the Netherlands.

\section{Address for correspondence}

Eibert R Heerdink, Utrecht University, Faculty of Science, Utrecht Institute for Pharmaceutical Sciences, Division of Pharmacoepidemiology and Pharmacotherapy, PO Box 80 082, 3508 TB Utrecht, the Netherlands. E-mail: e.r.heerdink@uu.nl

Submitted: 27 June 2008; Editor's response: 1 August 2008; final acceptance: 16 September 2008.

(c)British Journal of General Practice 2009; 59: 81-88. DOI: 10.3399/bjgp09X395067 
taking makes common sense in the light of their own understanding and beliefs about the illness and treatment.

Numerous studies have focused on patients who discontinue antidepressant use before the recommended duration of treatment. Between onethird and one-half of patients stop taking the antidepressant within 3 months, and less than half continue to take their antidepressant medication for a full 6 months..$^{3-8}$ Multiple factors have been hypothesised to be predictors of early discontinuation, including sociodemographic-, disease-, and treatment-related factors. ${ }^{4,8-13}$ However, initiation of antidepressant drug treatment has hardly been addressed in research. Often overlooked is the question of whether the patient collects the drug at the pharmacy, and whether the patient actually starts drug taking. It has been found that overall (that is, all prescriptions and all therapeutic groups), between $7 \%$ and $20 \%$ of patients fail to redeem their prescription at the pharmacy. ${ }^{14-16}$ These studies, however, do not provide insight into the non-filling of antidepressant prescriptions, and first-time prescriptions in particular. Furthermore, it has been shown that of all patients having an antidepressant dispensed at the pharmacy, up to $38 \%$ fill only a single prescription..$^{6,17-20}$ Of those filling only a single antidepressant prescription, onethird never initiate drug taking. ${ }^{3,20}$

To date, there have been no studies published that specifically explored the extent and determinants of declining the prescription for a new antidepressant treatment. The aim of this study therefore was to determine the incidence of patients who do not fill the first-time antidepressant prescription or redeem only a single antidepressant prescription at the pharmacy; and to identify patient characteristics associated therewith.

\section{METHOD}

\section{Study setting}

Data for this study were obtained by linkage of routine registration data collected in general practice to a pharmacy dispensing registration database. In the Netherlands, every individual is listed in a general practice. General practice data were obtained from the Second Dutch National Survey of General Practice (DNSGP-2), which was carried out in 2001 by the Netherlands Institute for Health Services Research (NIVEL) in cooperation with the National Institute for Public Health and the Environment (RIVM). The DNSGP-2 has been described in detail elsewhere. ${ }^{21}$ In short, 195 GPs in 104 practices registered details for all physician-patient contacts, including prescriptions and referrals, during 12 months in a standardised way. GPs were trained during an intensive course on coding practices and problems by the LINH (Dutch

\section{How this fits in}

Initiation of drug taking is a complicated process, as it involves patients and physicians making consecutive decisions. Often overlooked is the question of whether the patient collects the drug at the pharmacy, and whether the patient actually starts drug taking. This study found that over one in four patients who receive a first-time antidepressant prescription decline treatment, that is, they either do not initiate drug taking or do not persist with antidepressant use for longer than 2 weeks. Declining a first-time antidepressant prescription is more common in patients who consult their GP for a non-specific indication, in older and in non-Western immigrants.

Information Network GPs). The GPs registered and coded all health problems presented within a consultation according to the International Classification of Primary Care (ICPC). ${ }^{22}$ Furthermore, $76.5 \%$ of the total source population responded to a sociodemographic census with questions on health insurance, educational level, employment status, and perceived health. Most census data were collected in 2000. Pharmacy dispensing data were collected by the Foundation for Pharmaceutical Statistics (SFK). Medication histories of Dutch pharmacies are virtually complete because almost all patients fill their prescriptions, from GPs and medical specialists, at a single pharmacy. Data from both sources were linked by researchers from Utrecht University. ${ }^{23}$ In total, 110102 patients from 83 general practices participating in DNSGP-2 were identified in 112 pharmacies that delivered data to SFK. The SFK data include dispensing data for the patients from 1999 to 2003. Linking was based on the patient's sex, year of birth, postal code, and prescription characteristics. Prescription characteristics were used in the linking process because the other three linking keys did not provide unique matches for all patients. Linking GP prescribing and pharmacy dispensing data makes it possible to distinguish between drug prescribing and dispensing, which offers the possibility to assess whether prescriptions from the GP are collected at the pharmacy.

\section{Study population}

Subjects for the study were patients aged over 18 years, who received a first-time prescription for a second-generation antidepressant (selective serotonin reuptake inhibitor [SSRI], venlafaxine, or mirtazapine) from the GP in the year 2001. The date of the first antidepressant prescription that the patient received, as registered by the GP, was defined as the prescription date. First-time use was defined as having no antidepressant prescriptions dispensed, according to pharmacy dispensing data, in the 6 months before the prescription date of the study antidepressant. In the Netherlands, guidelines call for 
a 14-day supply for new prescriptions, and subsequent prescriptions are usually for a 30-day supply.

\section{Outcomes}

Three mutually exclusive outcomes were identified: patients who received an antidepressant prescription from the GP, but did not fill that prescription at the pharmacy (non-fillers); patients who filled only a single antidepressant prescription at the pharmacy (single Rx-fillers); and patients who filled at least two consecutive antidepressant prescriptions (initiators). Patients were defined as non-fillers when the first prescription was not dispensed at the pharmacy within 30 days of the prescription date. Patients were defined as single Rx-fillers when the first prescription was dispensed at the pharmacy, but not followed by a second antidepressant dispensing within 30 days after the theoretical end date of the first prescription. All other patients were defined as initiators. The theoretical end date equals the dispensing date of the prescription plus the theoretical duration of drug use, the latter being calculated by dividing the number of units of dispensed drug by prescribed daily dose.

\section{Determinants}

To identify patient characteristics associated with declining the first-time antidepressant prescription, three different types of determinants were explored: sociodemographic, health and morbidity, and medication-related characteristics.

\section{Sociodemographic characteristics}

Next to age and sex, social status, ethnicity, and living situation were included as sociodemographic characteristics. As indicators for social status, educational level (none/primary school versus secondary school versus college/university), type of health insurance (public versus private), and employment status (employed or in school versus not employed or in school), were included. Furthermore, first- and second-generation immigrants from nonWestern countries were compared to the combined population of Western immigrants and the indigenous Dutch population. Finally, variables for living situation (living alone versus living with partner and/or children) and marital status (unmarried versus married/registered partnership versus divorced versus widowed) were included.

\section{Health and morbidity characteristics}

The physician-patient contact registration includes information on the health problem for which the patient consulted the GP during the study period in the year 2001. The study assessed whether the patient visited the GP during this period due to specific indications for second-generation antidepressants: anxiety/panic disorder (P74), depression (P76), and obsessive-compulsive disorder (OCD)/phobia (P79). These indications are the officially approved indications for the second-generation antidepressants in the Netherlands. The antidepressant drug users could have more than one indication registered in the contact file. If the patient did not visit the GP for any of the specific indications (P74, P76, or P79), the patient was considered as having a non-specific indication for use, including, among others, feeling anxious (P01), depressive feelings (P03), and sleeping problems (P06). The presence of chronic disease and the total number of other chronic diseases for which the patient contacted the GP during 6 months before the prescription date, were also assessed. Furthermore, the total number of contacts the patient had with the GP during the 6 months prior to prescription date, and whether the patient consulted the GP within 28 days after the prescription date, were investigated. Finally, a first referral to a psychotherapist during the study period, and information on self-perceived health (very poor/poor versus moderate versus good/excellent), were included.

\section{Medication-related characteristics}

Included as medication characteristics were type of prescribed antidepressant, any use of psychotropic co-medication (benzodiazepines or antipsychotics), and the number of other co-medications during the 6 months before the prescription date. Co-medication variables were obtained from the pharmacy dispensing registration database.

\section{Data analysis}

For the analysis, non-fillers and single Rx-fillers, were combined into a group of decliners, that is patients who did not fill the prescription, patients who did fill the prescription but did not start drug taking, and patients who filled the prescription but did not persist with antidepressant use for longer than 2 weeks. $\chi^{2}$ test (for the categorical measures) and independentsamples $t$-test (for the continuous measures) were used to compare the characteristics between decliners and initiators, and between non-fillers and single Rx-fillers. To control for covariates and identify the risk factors for declining a first-time antidepressant prescription, multivariate logistics regression analysis was performed in the group of patients for which consultation, dispensing, and patient census data were available $(n=671)$. Covariates that were significant in the univariate analysis at a $P$-value less than 0.1 , including patient sex, were included in the logistic regression model. Data were analysed using SPSS (version 14.0). 


\section{RESULTS}

Of all 965 patients receiving a first-time prescription for a second-generation antidepressant in general practice, $41(4.2 \%)$ did not fill that prescription at the pharmacy (non-fillers), and 229 (23.7\%) filled only a single prescription (single Rx-fillers). The mean age of all patients was 48.5 years ( \pm standard deviation 16.8 years) and $657(68.1 \%)$ were female. Of all patients, 517 (53.6\%) were prescribed paroxetine, 98 (10.2\%) fluvoxamine, 87 (9.0\%) mirtazapine, 86 (8.9\%) fluoxetine, 74 (7.7\%) citalopram, 74 (7.7\%) venlafaxine, and $29(3.0 \%)$ sertraline.

\section{Table 1. Characteristics of patients who receive a first-time antidepressant prescription in general practice: non-fillers, single Rx-fillers, and initiators.}

\begin{tabular}{|c|c|c|c|c|c|}
\hline \multirow[b]{2}{*}{ Measures } & \multicolumn{2}{|c|}{ Decliners $^{\mathrm{a}}, n=270(72.0 \%)$} & \multirow[b]{2}{*}{$\begin{array}{l}\text { Initiators }, n=695 \\
(28.0 \%)\end{array}$} & \multirow[b]{2}{*}{$\begin{array}{l}\text { Decliners versus } \\
\text { initiators, } P \text {-value }\end{array}$} & \multirow[b]{2}{*}{$\begin{array}{l}\text { Non-fillers versus single } \\
\text { Rx-fillers, } P \text {-value }\end{array}$} \\
\hline & $\begin{array}{l}\text { Non-fillers } \\
n=41(4.2 \%)\end{array}$ & $\begin{array}{l}\text { Single Rx-fillers }{ }^{\circ} \\
n=229(23.7 \%)\end{array}$ & & & \\
\hline \multicolumn{6}{|l|}{ Sociodemographic characteristics } \\
\hline Female sex, $n(\%)$ & $35(85.4)$ & $151(65.9)$ & $471(67.8)$ & 0.74 & 0.01 \\
\hline \multicolumn{6}{|l|}{ Age in years, $n(\%)$} \\
\hline $18-30$ & $3(7.3)$ & $34(14.8)$ & $93(13.4)$ & 0.08 & 0.33 \\
\hline $31-45$ & $11(26.8)$ & $71(31.0)$ & $254(36.5)$ & & \\
\hline $46-60$ & $12(29.3)$ & $67(29.3)$ & $212(30.5)$ & & \\
\hline$>60$ & $15(36.6)$ & $57(24.9)$ & $136(19.6)$ & & \\
\hline \multicolumn{6}{|l|}{ Educational level, ${ }^{\dagger} n(\%)$} \\
\hline None/primary school & $5(20.0)$ & 47 (31.1) & $93(19.4)$ & 0.01 & 0.37 \\
\hline Secondary school & $15(60.0)$ & $86(57.0)$ & $294(61.3)$ & & \\
\hline College/university & $5(20.0)$ & $18(11.9)$ & $93(19.4)$ & & \\
\hline Employed or in school, ${ }^{\dagger} n(\%)$ & $9(34.6)$ & 69 (46.6) & $248(51.3)$ & 0.14 & 0.26 \\
\hline Non-Western background, ${ }^{\dagger} n(\%)$ & $2(7.7)$ & $18(11.8)$ & $13(2.6)$ & $<0.001$ & 0.54 \\
\hline \multicolumn{6}{|l|}{ Marital status, ${ }^{\dagger} n(\%)$} \\
\hline Unmarried & $8(30.8)$ & $32(21.2)$ & $114(23.3)$ & 0.33 & 0.43 \\
\hline Married/registered partnership & $16(61.5)$ & 90 (59.6) & $312(63.8)$ & & \\
\hline Divorced & $1(3.8)$ & $9(6.0)$ & $27(5.5)$ & & \\
\hline Widowed & $1(3.8)$ & $20(13.2)$ & $36(7.4)$ & & \\
\hline Living together & $21(80.8)$ & $114(75.5)$ & $398(81.4)$ & 0.14 & 0.56 \\
\hline Public health insurance, $n(\%)$ & $30(73.2$ & $181(79.0)$ & $525(75.5)$ & 0.64 & 0.53 \\
\hline \multicolumn{6}{|l|}{ Health and morbidity-related characteristics } \\
\hline $\begin{array}{l}\text { Specific indication for prescribing } \\
\text { antidepressant: depression, anxiety, panic, } \\
\text { or OCD, } n(\%)\end{array}$ & $24(58.5)$ & $128(55.9)$ & $506(72.8)$ & $<0.001$ & 0.75 \\
\hline \multicolumn{6}{|l|}{ Self-perceived health, $n$ (\%) } \\
\hline Very poor/poor & $0(0)$ & $20(13.9)$ & $30(6.5)$ & 0.06 & 0.02 \\
\hline Moderate & $13(52.0)$ & $41(28.5)$ & $140(30.2)$ & & \\
\hline Good/excellent & $12(48.0)$ & $83(57.6)$ & $293(63.3)$ & & \\
\hline Psychotherapy, $n$ (\%) & $6(14.6)$ & 27 (11.8) & 79 (11.4) & 0.71 & 0.61 \\
\hline Other chronic diseases, $n(\%)$ & $15(36.5)$ & $63(27.5)$ & $180(25.9)$ & 0.35 & 0.24 \\
\hline Number of other chronic diseases, mean (SD) & $0.5(0.7)$ & $0.4(0.8)$ & $0.4(0.7)$ & 0.21 & 0.67 \\
\hline $\begin{array}{l}\text { Number of contacts with GP in previous } \\
6 \text { months, mean (SD) }\end{array}$ & $5.1(4.6)$ & $5.1(5.7)$ & $4.8(5.2)$ & 0.44 & 0.99 \\
\hline $\begin{array}{l}\text { Contact with GP within } 28 \text { days after } \\
\text { prescription date, } n(\%)\end{array}$ & $25(61.0)$ & $107(46.7)$ & $487(70.1)$ & $<0.001$ & 0.09 \\
\hline \multicolumn{6}{|l|}{ Medication-related characteristics } \\
\hline $\begin{array}{l}\text { Use of paroxetine (versus other } \\
\text { antidepressants), } n(\%)\end{array}$ & $17(41.5)$ & $113(49.3)$ & $387(55.7)$ & 0.04 & 0.35 \\
\hline \multicolumn{6}{|l|}{ Co-medication, $n$ (\%) } \\
\hline Benzodiazepines & $14(34.1)$ & $89(38.9)$ & $279(40.1)$ & 0.57 & 0.57 \\
\hline Antipsychotics and lithium & $1(2.4)$ & $9(3.9)$ & $18(2.6)$ & 0.36 & 0.64 \\
\hline Number of co-medicines, mean (SD) & $3.2(2.9)$ & $3.9(4.1)$ & $3.5(3.8)$ & 0.35 & 0.33 \\
\hline
\end{tabular}


Table 2. Characteristics associated with declining the GP's prescription: patients who do not fill the firsttime antidepressant prescription or fill only a single antidepressant prescription at the pharmacy. ${ }^{\mathrm{a}}$

\begin{tabular}{lcccc} 
& Crude OR & $95 \% \mathrm{Cl}$ & Adjusted $\mathrm{OR}^{\mathrm{b}}$ & $95 \% \mathrm{Cl}^{\mathrm{b}}$ \\
\hline $\begin{array}{l}\text { Non-specific indication for prescribing antidepressant } \\
\text { (rc indication of depression, anxiety, panic, or OCD) }\end{array}$ & 2.61 & 1.80 to 3.78 & 2.67 & 1.82 to 3.91 \\
\hline Non-Western immigrants (rc Western origin) & 3.67 & 1.63 to 8.25 & 4.80 & 2.05 to 11.3 \\
\hline Age $>60$ years (rc all other ages) & 1.75 & 1.17 to 2.63 & 1.81 & 1.18 to 2.78 \\
\hline Female (rc male) & 0.96 & 0.65 to 1.42 & 0.92 & 0.61 to 1.39 \\
\hline Educational level precollege (rc college/university) & 1.53 & 0.93 to 2.52 & 1.40 & 0.83 to 2.36 \\
\hline Self-rated health poor/ moderate (rc good/excellent) & 1.33 & 0.93 to 1.91 & 1.11 & 0.76 to 1.63 \\
\hline Paroxetine prescribed (rc other antidepressants) & 0.72 & 0.51 to 1.03 & 0.78 & 0.53 to 1.13 \\
\hline
\end{tabular}

'Multivariate logistics regression analysis was performed in the group of patients for which GP consultation, drug dispensing, and patients' census data were available $(n=671)$. 'Odds ratios adjusted for the variables shown in this table, that is, the covariates that are significant in the univariate analysis at a P-value less than 0.1 , including patient sex. $r c=$ reference category. $O C D=$ obsessive compulsive disorder. $O R=$ odds ratio.

Table 1 shows the sociodemographic, health and morbidity, and medication-related characteristics for the non-fillers, single Rx-fillers, and initiators. Nonfillers and single Rx-fillers were combined into a group of decliners, and compared with the group of initiators. For 671 patients $(69.5 \%$ of all), census data were available.

The results of the multivariate logistic regression analysis for the association between patient characteristics and declining the prescription are shown in Table 2. Patients who consulted their GP for a non-specific indication, rather than for depression, anxiety, panic, or OCD, were almost three times more likely (odds ratio $[\mathrm{OR}]=2.67,95 \%$ confidence interval $(\mathrm{Cl})=1.82$ to 3.91$)$ to decline the antidepressant prescription. In half of the cases, the decliners were not diagnosed with either depression, anxiety, panic, or OCD; $24.4 \%$ consulted the GP for the indications feeling depressed, feeling anxious or sleeping problems, and $19.3 \%$ for other non-specific indications, such as fatigue, weight loss and relationship problems. Of all patients diagnosed with the indications feeling depressed, feeling anxious, or sleeping problems, $33.8 \%$ declined treatment, and of all patients considered having any other non-specific indications, $46.4 \%$ did so. In addition, the risk of declining treatment was almost five times higher (OR $4.80,95 \% \mathrm{Cl}=2.05$ to 11.3 ) in non-Western immigrants, and almost two times higher $(\mathrm{OR}=1.81$, $95 \% \mathrm{Cl}=1.18$ to 2.78 ) in patients $>60$ years of age. Overall, the decliners were less likely to consult the GP within 4 weeks after the prescription date, compared to the initiators. However, comparing the non-fillers and single Rx-fillers, there was a trend that non-fillers were more likely to consult the GP within 4 weeks after the prescription date.

\section{DISCUSSION}

\section{Summary of main findings}

The study findings demonstrate the importance of the initiation phase of antidepressant therapy, which has often been overlooked in previous research. Over one in four patients receiving a first-time antidepressant prescription from their GP decline treatment: $4.2 \%$ do not fill the prescription at the pharmacy, and $23.7 \%$ fill only a single prescription. Declining the first-time antidepressant prescription is more common in patients who consult their GP for a non-specific indication, such as feeling depressed, sleeping problems, fatigue, or relationship problems, rather than for the specific indications depression, anxiety, panic, or OCD. In addition, non-Western immigrants and patients $>60$ years of age were more likely to decline treatment.

\section{Strength and limitations of the study}

The strength of this study is the availability of the population-based dataset, which combines GPconsultation, drug-dispensing, and patient-census data, thereby providing more patient-specific information. Linking GP-prescribing and pharmacydispensing data enabled determination of the incidence of patients who do not fill their first-time antidepressant prescription. Studies on drug adherence often measure persistence, defined as the time between the first and last taken dose. These studies, however, often exclude patients who do not fill or fill only a single prescription. In view of the considerable number of patients concerned, namely over one in four patients receiving a prescription for a new treatment, the findings from previous studies need to be placed in a different perspective. Furthermore, in contrast to most regular dispensing databases, this study had information on the indications for which the patient consulted the GP, which have been shown to be very relevant.

The main weakness of the study is the lack of insight into the decision-making process in the clinical encounters, and into the patients' decision to decline treatment. The study does not provide information on 
the reasons for not filling or filling only a single prescription, and on whether decline of treatment was intentional or unintentional. Furthermore, it is not known whether the GP was involved or informed of patients' decision to decline treatment. It is, however, unlikely that patients who do not fill their prescription at the pharmacy or fill only a single prescription discuss their decision to decline the prescription with the GP. Previous studies showed that more than half of the patients discontinuing antidepressant treatment in an early stage do not feel the need to inform their GP of stopping. ${ }^{7,20,24}$

\section{Comparison with existing literature}

Patients with non-specific psychological symptoms are more likely to decline the first-time antidepressant prescription. In clinical practice, antidepressants are prescribed for a broad range of indications, including mental and psychological problems other than depression or anxiety. ${ }^{12,25,26}$ Antidepressants used for indications other than depression and anxiety have been shown to be correlated with discontinuation of drug taking. ${ }^{12,26}$ The present study shows that the indication is an important factor during the initiation phase of treatment as well.

There may be several reasons for patients declining antidepressant drug therapy. First, the patient and GP may not have a shared understanding of the problem and its treatment, so the patient does not have the prescription dispensed. There seems to be a disparity between patients' attitude towards antidepressant treatment and GPs' perceptions of their attitudes..$^{27,28}$ GPs generally see the depressive symptoms against a background of the patient's family history, physical illness, life events, and degree of disability. ${ }^{29,30}$ They seem to use non-specific clinical cues such as distress and impairment, as well as their knowledge of the patient, in diagnosing the illness..$^{31}$ Mild depressive symptoms and psychological emotional problems can be associated with significant functional impairment, which physicians may feel inclined to address. ${ }^{30}$ Patients, however, may not all expect to receive a prescription when consulting the physician. ${ }^{32}$ Studies have shown that the majority of patients in general practice prefer treatment approaches for emotional problems that go beyond antidepressant medication. ${ }^{33-35}$ Most of them just expect the GP to listen to their problems and hope for an understanding attitude. ${ }^{36}$ Second, the patient may agree with the decision to prescribe treatment, but changes his or her mind in the light of further information or conversations with others. These patients may either not dispense the prescription or not initiate antidepressant drug taking. Finally, the patient may start taking antidepressants, but stop them quickly. In a previous study in patients filling only a single prescription of an SSRI, it was shown that fear of sideeffects and the actual occurrence of side-effects are the main reasons for not filling a second prescription. ${ }^{20}$ Antidepressant side-effects may occur immediately after starting to take the drug, while it usually takes some weeks before patients experience recovery of symptoms. ${ }^{37}$ The side-effects from the drug treatment can make people feel worse at first. An aversion towards medicine use, and feeling better in the meantime, were considerable reasons for not taking the medication for longer than 2 weeks. ${ }^{20}$

This study also showed that non-Western immigrants and patients aged $>60$ years were more likely to decline the antidepressant prescription. In both groups, declining the prescription might be attributed to a lack of understanding about the illness and treatment. Non-Western immigrants may have difficulties communicating in Dutch, but cultural factors may also influence patients' attitude towards drug taking. ${ }^{38}$ A study in the same Dutch population found non-Western immigrants to be more vulnerable for non-adherence in a later stage of treatment as well. ${ }^{12}$ Both the mentioned study and a study by Hansen et al, however, do not observe an influence of age on early discontinuation..$^{12,18}$ However, the greater proportion of patients included in these studies used the medication for longer than 14 days, which was the maximum duration of use for the majority of patients in this study. The Dutch study further showed that women were less likely to be early dropouts. The present study found in the same population an effect of patient sex only in the group of non-fillers, that is women were more likely not to fill their prescription at the pharmacy. Finally, in contrast to the results from the Danish study, which reported a higher risk for early discontinuation in patients of low socioeconomic status, the present study did not find a clear effect of sociodemographic characteristics on declining the first-time prescription.

\section{Implications for clinical practice and future research}

The present findings imply that initiation of antidepressant therapy deserves more attention in research and clinical practice. Over one in four patients who receive a first-time antidepressant prescription decline treatment. More research is needed into the implications of declining antidepressant treatment. In addition, the decisionmaking process in clinical encounters, especially considering the perspective of the patient, requires attention. In practice, GPs could be more aware of the possibility of patients declining a first-time antidepressant prescription. They need to engage with patients' priorities and concerns, and could ask patients whether they believe an antidepressant would be helpful in treating their symptoms. 


\section{Funding body}

No funding was received for this study

\section{Ethical approval}

The study was carried out according to Dutch legislation on privacy. The privacy regulation was approved by the Dutch Data Protection Authority. According to Dutch legislation, obtaining informed consent is not obligatory for observational studies

\section{Competing interests}

The authors have stated that there are none

\section{Acknowledgements}

We thank NIVEL, the Netherlands Institute for Health Services Research, for providing the data, and Patrick Souverein for his assistance with data management.

\section{Discuss this article}

Contribute and read comments about this article on the Discussion Forum: http://www.rcgp.org.uk/bjgp-discuss

\section{REFERENCES}

1. Donovan JL, Blake DR. Patient non-compliance: deviance or reasoned decision-making? Soc Sci Med 1992; 34(5): 507-513.

2. Horne R, Weinman J. Patients' beliefs about prescribed medicines and their role in adherence to treatment in chronic physical illness. $J$ Psychosom Res 1999; 47(6): 555-567.

3. Bull SA, Hunkeler EM, Lee JY, et al. Discontinuation or switching selective serotonin-reuptake inhibitors. Ann Pharmacother 2002; 36(4) 578-584.

4. Lin EHB, Von Korff M, Katon W, et al. The role of the primary care physician in patients' adherence to antidepressant therapy. Med Care 1995; 33(1): 67-74

5. Demyttenaere K, Enzlin P, Dewé W, et al. Compliance with antidepressants in a primary care setting, 1: beyond lack of efficacy and adverse events. J Clin Psychiatry 2001; 62(suppl 22): 30-33.

6. Meijer WEE, Heerdink ER, Leufkens HMG, et al. Incidence and determinants of long-term use of antidepressants. Eur J Clin Pharmacol 2004; 60(1): 57-61.

7. Maddox JC, Levi M, Thompson C. The compliance with antidepressants in general practice. J Psychopharmacol 1994; 8(suppl 1): 48-53.

8. Olfson M, Marcus SC, Tedeschi M, Wan GJ. Continuity of antidepressant treatment for adults with depression in the United States. Am J Psychiatry 2006; 163(1): 101-108.

9. Demyttenaere K, Enzlin P, Dewé W, et al. Compliance with antidepressants in a primary care setting, 2: the influence of gender and type of impairment. J Clin Psychiatry 2001; 62(suppl 22): 34-37.

10. Cohen N, Parikh SV, Kennedy SH. Medication compliance in mood disorders: relevance of the Health Belief Model and other determinants. Prim Care Psychiatry 2000; 6: 101-110.

11. Lingam R, Scott J. Treatment non-adherence in affective disorders. Acta Psychiatr Scand 2002; 105: 164-172.

12. Van Dijk L, Heerdink ER, Somai D, et al. Patient risk profiles and practice variation in nonadherence to antidepressants, antihypertensives and oral hypoglycemics. BMC Health Serv Res 2007; 7: 51.
13. Sirey JO, Bruce ML, Alexopoulos GS, et al. Stigma as a barrier to recovery: Perceived stigma and patient-rated severity of illness as predictors of antidepressant drug adherence. Psychiatr Serv 2001; 52(12): 1615-1620

14. Waters WHR, Gould NV, Lunn JE. Undispensed prescriptions in a mining general practice. BMJ 1976; 1(6071): 1062-1063.

15. Rashid A. Do patients cash prescriptions? BMJ 1982; 284(6308):24-26.

16. Beardon PHG, McGilchrist MM, McKendrick AD, et al. Primary noncompliance with prescribed medication in primary care. BMJ 1993; 307(6908): 846-848.

17. McGettigan P, Kelly A, Carvahlo M, Feely J. Antidepressants in primary care: analysis of treatment discontinuations. Pharmacoepidemiol Drug Saf 2000; 9: 521-528.

18. Hansen GH, Vach W, Rosholm J-U, et al. Early discontinuation of antidepressants in general practice: association with patient and prescriber characteristics. Fam Pract 2004; 21(6): 623-629.

19. Simon GE, VonKorff M, Wagner EH, Barlow W. Patterns of antidepressant use in community practice. Gen Hosp Psychiatry 1993; 15(6): 399-405

20. Van Geffen ECG, van Hulten R, Bouvy ML, et al. Characteristics and reasons associated with nonacceptance of selective serotonin-reuptake inhibitor treatment. Ann Pharmacother 2008; 42(2): 218-225.

21. Westert GP, Schellevis FG, de Bakker DH, et al. Monitoring health inequalities through general practice: the Second Dutch Survey of General Practice. Eur J Public Health 2005; 15(1): 59-65.

22. Lamberts $\mathrm{H}$, Wood M. International classification of primary care. Oxford: Oxford University Press, 1987.

23. Florentinus SR, Souverein PC, Griens AMGF, et al. Linking community pharmacy dispensing data to prescribing data of general practitioners. BMC Health Serv Res 2006; 6: 18

24. Bull SA, Hu XH, Hunkeler EM, et al. Discontinuation of use and switching of antidepressants: influence of patient-physician communication. JAMA 2002; 288(11): 1403-1409.

25. Gardarsdottir H, Heerdink ER, van Dijk L, Egberts ACG. Indications for antidepressant drug prescribing in general practice in the Netherlands. $J$ Affect Disord 2007; 98(1-2): 109-115.

26. Pomerantz JM, Finkelstein SN, Berndt ER, et al. Prescriber intent, offlabel usage, and early discontinuation of antidepressants: a retrospective physician survey and data analysis. J Clin Psychiatry 2004; 65(3): 395-404

27. Hyde J, Calnan M, Prior L, et al. A qualitative study exploring how GPs decide to prescribe antidepressants. Br J Gen Pract 2005; 55(519): $755-762$

28. Kendrick T, King F, Albertella L, Smith PWF. GP treatment decisions fo patients with depression: an observational study. Br J Gen Pract 2005; 55(513): 280-286

29. Anonymous. Mild depression in primary care: time for a rethink? Drug Ther Bull 2003; 41(10): 60-64.

30. Chew-Graham CA, May CR, Cole H, Hedley S. The burden of depression in primary care: a qualitative investigation of general practitioners' constructs of depressed people in the inner city. Prim Care Psychiatry 2000; 6: 137-141.

31. Klinkman MS, Coyne JC, Gallo S, Schwenk TL. False positive, false negative, and the validity of the diagnosis of major depression in primary care. Arch Fam Med 1998; 7(5): 451-461.

32. Britten N. Patient demands for prescriptions: a view from the other side. Fam Pract 1994; 11(1): 62-66.

33. Lowe B, Schultz U, Grafe K, Wilke S. Medical patients' attitudes toward emotional problems and their treatment. What do they really want? J Gen Intern Med 2006; 21(1): 39-45.

34. Van Schaik DJF, Klijn AFJ, van Hout HPJ, et al. Patients' preferences in the treatment of depressive disorder in primary care. Gen Hosp Psychiatry 2004; 26(3): 184-189.

35. Walters K, Buszewicz M, Weich S, King M. Help-seeking preferences for psychological distress in primary care: effect of current mental state. $\mathrm{Br} \mathrm{I}$ Gen Pract 2008; 58: 694-698.

36. Backenstrass M, Joest K, Rosemann T, Szecsenyi J. The care of patients with subtreshold depression in primary care: is it all that bad? A qualitative study on the views of general practitioners and patients. BMC Health Serv Res 2007; 7: 190.

37. Hansen HV, Kessing LV. Adherence to antidepressant treatment. Expert Rev Neurother 2007; 7(1): 57-62.

38. Uiters E, van Dijk L, Deville WD, et al. Ethnic minorities and prescription medication; concordance between selfreports and medical records. BMC Health Serv Res 2006; 6: 115 